\title{
O lugar dos museus e o direito à cidade: um estudo sobre espaço, tempo e trabalho
}

\author{
Wagner Miquéias Damasceno ${ }^{1}$
}

\begin{abstract}
Resumo
Este estudo trata da relação entre a localização geográfica dos museus e a visitação. Analiso os obstáculos à visitação dos museus brasileiros por parte da classe trabalhadora e pobre, considerando as assimetrias entre a localização dos museus e a produção e apropriação espacial nas grandes cidades e compreendendo essa relação a partir do conceito do geógrafo David Harvey, de desenvolvimento geográfico desigual. Para tanto, trabalharei numa perspectiva interdisciplinar conjugando elaborações da Sociologia, Museologia e Geografia. Utilizarei dados das pesquisas do Instituto de Pesquisa Econômica Aplicada (IPEA) sobre cultura, mobilidade urbana, trabalho e tempo livre e, também, da pesquisa Museus em Números, do Instituto Brasileiro de Museus (IBRAM).
\end{abstract}

Palavras-chave: Museus, equipamentos culturais, mobilidade urbana, geopolítica, trabalho.

\begin{abstract}
This study deals with the relationship between the geographic location of museums and visitors. Analyze barriers to visitation of Brazilian museums by the working class and poor, considering the asymmetries between the location of museums and the production and spatial appropriation in major cities comprising this relationship from the geographer concept David Harvey, of uneven geographical development To this end, I will work in an interdisciplinary perspective combining
\end{abstract}

\footnotetext{
${ }^{1}$ Doutorando em Sociologia pela Universidade Estadual de Campinas (UNICAMP). wagnermiqueias@yahoo.com.br
} 
elaborations of Sociology, Geography and Museology. I will use survey data from the Institute of Applied Economic Research (IPEA) on culture, urban mobility, work and free time and also the search Museums in numbers, the Brazilian Institute of Museums (IBRAM).

Keywords: museums, cultural equipment, urban mobility, geopolitic, work.

\section{Introdução}

Neste estudo, parto das categorias tempo, trabalho e espaço para refletir sobre as condições sociais no Brasil para a visitação de museus. Para tanto, utilizarei os dados obtidos através do Cadastro Nacional de Museus, presentes no Museus em Número, do Instituto Brasileiro de Museus (IBRAM) e no Sistema de Indicadores de Percepção Social: Trabalho e tempo livre e no Sistema de Indicadores de Percepção Social: Cultura do Instituto de Pesquisa Econômica Aplicada (IPEA). Trabalharei nos marcos da Sociologia do Trabalho e da Museologia Social, e me apoiarei nas elaborações da Geografia crítica, em Milton Santos, Alvaro Ferreira e em David Harvey.

\section{A construção social do espaço}

Para o eminente geógrafo brasileiro Milton Santos, o "espaço geográfico é a natureza modificada pelo homem mediante seu trabalho" (2012, p. 150). Neste sentido, o espaço que lhe despertou interesse científico era o espaço humano ou social.

O espaço deve ser considerado como um conjunto de relações realizadas através de funções e de formas que se apresentam como testemunho de uma história escrita por processos do passado e do presente. Isto é, o espaço se define como um conjunto de formas representativas de relações sociais do passado e do presente e por uma estrutura representada por relações sociais que 
estão acontecendo diante dos nossos olhos e que se manifestam através de processos e funções. 0 espaço é, então, um verdadeiro campo de forças cuja aceleração é desigual. Daí por a evolução espacial não se faz de forma idêntica em todos os lugares (SANTOS, 2012, p. 151).

Rompendo com uma visão determinista que consagrara o espaço como uma categoria dada e independente da ação humana/social, Milton Santos apresentou uma concepção humanista que pode ser prenhe de sentidos para a Museologia.

Ademais, o espaço se define, não só, por uma estrutura representada por relações sociais que estão acontecendo diante dos nossos olhos, mas também, por relações sociais que "passam por nossas costas". De tal sorte, construímos o espaço mesmo quando não temos compreensão exata de que o fazemos, e extraímos dele percepções que não se encerram na compreensão individual da nossa ação.

O ponto de partida deve ter em conta que o espaço é um produto social e nesse sentido, o processo de construção da cidade constitui-se como produto e como condição dos processos sociais em curso. Em outras palavras, estamos dizendo que os citadinos produzem o espaço mas são também dominados e coagidos pela sua própria criação (FERREIRA, 2011, p. 152).

O espaço não é um mero dado da natureza. Isto é, o espaço não é algo "natural"2, mas uma síntese de múltiplas determinações de ordem social e natural. Assim, os lugares

\footnotetext{
${ }^{2}$ Aliás, como ressalta Porto-Gonçalves (2008), o próprio conceito de natureza não é natural: "Toda sociedade, toda cultura cria, inventa, institui uma determinada idéia do que seja a natureza. Nesse sentido, o conceito de natureza não é natural, sendo na verdade criado e instituído pelos homens" (p. 23).
} 
seriam porções discretas do espaço total, "uma porção da face da terra identificada por um nome. Aquilo que torna o 'lugar' específico é um objeto material ou um corpo" (SANTOS, 2012, p. 152). Para Santos (2012), essa porção de um espaço total é dependente e integra a totalidade de lugares que constroem o espaço.

A localização dos museus também não é algo natural. Sendo assim, a compreensão da disposição dos museus e espaços museológicos nas cidades é condição basilar para os estudos de público, revelando o caráter interdisciplinar e integrador da Museologia enquanto campo de estudos.

\section{A localização dos equipamentos culturais nas cidades brasileiras}

O Instituto de Pesquisa Econômica e Aplicada (IPEA) realizou, no ano de $2010^{3}$, uma pesquisa intitulada Sistema de Indicadores de Percepção Social - Cultura (SIPS) com os seguintes objetivos: compreender a percepção social sobre a organização urbana para a prática cultural; as disposições culturais para o uso do tempo; as percepções a respeito da oferta cultural; a frequência de práticas culturais. A hipótese que orientou essa pesquisa é a de que as dinâmicas e os contextos sociais urbanos constituem variáveis relevantes para o entendimento da produção e, sobretudo, fruição cultural.

A cultura é um plano de observação privilegiado para olhar as cidades e os dinamismos que as movem. Os contextos urbanos induzem processos específicos de desenvolvimento cultural, de transformação de práticas e de condicionamentos particularmente importantes dos usos dados ao tempo livre (2010, p. 01).

\footnotetext{
${ }^{3} \mathrm{Em}$ que pese a data, até o momento, trata-se do mais amplo e recente estudo sobre o tema em nível nacional.
} 
Tendo como eixo da pesquisa o conceito de referencial, o IPEA apresentou alguns resultados gerais relativos à percepção ${ }^{4}$ sobre a localização de diferentes espaços de sociabilidade, como mostra a tabela 2.

Tabela 01 - Percepção a respeito da localização de espaços para práticas culturais e sociais

\begin{tabular}{|l|l|l|l|l|l|}
\hline $\begin{array}{l}\text { Localização por proximidade } \\
\text { de onde mora }\end{array}$ & $\begin{array}{l}\text { Muito bem } \\
\text { situado }\end{array}$ & $\begin{array}{l}\text { Razoavelmente } \\
\text { bem situado }\end{array}$ & $\begin{array}{l}\text { Mal } \\
\text { situado }\end{array}$ & $\begin{array}{l}\text { Não } \\
\text { tem }\end{array}$ & NS/NR \\
\hline Espaços verdes & 30,7 & 36,5 & 31,0 & 0,3 & 1,4 \\
\hline Equipamentos esportivos & 20,1 & 31,0 & 43,2 & 1,5 & 4,2 \\
\hline Equipamentos culturais & 15,7 & 26,4 & 51,0 & 1,5 & 5,4 \\
\hline Comércios & 59,5 & 30,6 & 9,1 & 0,1 & 0,7 \\
\hline $\begin{array}{l}\text { Localização dos lugares de } \\
\text { encontro e vida associativa }\end{array}$ & 20,9 & 32,0 & 40,8 & 1,4 & 2,7 \\
\hline
\end{tabular}

Tabela Adaptada. Fonte: Pesquisa SIPS - IPEA, 2010.

Observa-se que a percepção acerca da localização dos equipamentos culturais ${ }^{5}$ apresenta os maiores percentuais negativos: $51 \%$ dos entrevistados entende que os equipamentos culturais estão mal localizados. Esses percentuais são ligeiramente maiores quando consideramos as regiões do país: no Sul, 55,3\% dos entrevistados consideram que os equipamentos culturais são mal localizados, $53,8 \%$ no Sudeste, $44,5 \%$ no CentroOeste, $51,2 \%$ no Nordeste e $43,4 \%$ no Norte (IPEA, 2010).

Observa-se que as percepções daqueles que recebem acima de 5 salários mínimos sobre a localização dos equipamentos é,

\footnotetext{
${ }^{4} \mathrm{O}$ estudo do IPEA utilizou uma técnica de amostragem por cotas, visando representatividade e operacionalidade. A amostra consistiu em 2.270 domicílios das quatro regiões do país, com margem de erro de $1,86 \%$. Ver:

http://www.ipea.gov.br/portal/images/stories/PDFs/SIPS/120418_sips_metodol ogia.pdf.

${ }^{5}$ Refere-se a Cinemas, Bibliotecas, Museus, Centros Culturais, Casas de Espetáculo etc.
} 
em geral, mais positiva, embora os números não apresentem uma diferença expressiva, como é o caso dos equipamentos culturais. Conforme a tabela acima, 15,9\% daqueles que ganham até dois salários mínimos opinaram que estão muito bem situados em relação aos equipamentos culturais, e 17,1\%, daqueles que recebem acima de cinco salários mínimos, estão muito bem situados.

Os valores apresentados na tabela 04 demonstram grande homogeneidade de percepção entre pessoas com diferentes níveis de escolaridade quanto à distribuição dos equipamentos sociais (comércio, lugares de encontro, equipamentos culturais, espaços verdes e equipamentos esportivos). Isto é, aproximadamente metade dos entrevistados consideram que estão mal situados em relação à localização dos equipamentos culturais. 
Tabela 02 - Percepção dos espaços para práticas culturais e sociais por classes de renda ${ }^{6}$

\begin{tabular}{|c|c|c|c|c|}
\hline \multirow[t]{2}{*}{ Espaços } & \multirow{2}{*}{$\begin{array}{ll}\text { Categoria } & \text { de } \\
\text { percepção } & \end{array}$} & \multicolumn{3}{|c|}{ Renda familiar mensal } \\
\hline & & $\begin{array}{l}\text { Até 2SM (até } \\
\mathrm{R} \$ 1.020,00)\end{array}$ & $\begin{array}{l}+ \text { de } 2 \text { a } 5 S M \\
\text { (de } R \$ 1.020 \text { a } \\
R \$ 2.250)\end{array}$ & $\begin{array}{l}+ \text { de } 5 S M \text { (de } \\
R \$ 2.250 \quad \text { e } \\
\text { mais) }\end{array}$ \\
\hline \multirow[t]{3}{*}{ Espaços verdes } & Muito bem & 29,3 & 30,2 & 33,4 \\
\hline & Razoavelmente & 34,4 & 37,6 & 37,7 \\
\hline & Mal situado & 34,5 & 30,8 & 26,7 \\
\hline \multirow[t]{3}{*}{ Equipamentos esportivos } & Muito bem & 19,8 & 18,0 & 23,4 \\
\hline & Razoavelmente & 29,7 & 31,2 & 32,4 \\
\hline & Mal situado & 44,5 & 44,9 & 39,1 \\
\hline \multirow[t]{3}{*}{ Equipamentos culturais } & Muito bem & 15,9 & 14,5 & 17,1 \\
\hline & Razoavelmente & 23,7 & 27,0 & 29,0 \\
\hline & Mal situado & 52,7 & 51,7 & 47,8 \\
\hline \multirow{3}{*}{$\begin{array}{l}\text { Localização dos lugares } \\
\text { de encontro e vida } \\
\text { associativa }\end{array}$} & Muito bem & 20,5 & 20,5 & 22,2 \\
\hline & Razoavelmente & 29,2 & 31,4 & 36,5 \\
\hline & Mal situado & 42,9 & 42,3 & 36,1 \\
\hline \multirow[t]{3}{*}{ Comércios } & Muito bem & 57,5 & 58,9 & 63,0 \\
\hline & Razoavelmente & 30,6 & 32,0 & 28,7 \\
\hline & Mal situado & 11,1 & 8,3 & 7,5 \\
\hline
\end{tabular}

Tabela Adaptada. Fonte: Pesquisa SIPS - IPEA, 2010.

\footnotetext{
${ }^{6}$ Divirjo da consideração expressa nesse estudo do IPEA que toma aqueles que recebem até dois salários mínimos e aqueles que recebem mais de cinco salários mínimos como membros de classes sociais diferentes. Primeiro porque o conceito de classe social não se resume aos rendimentos auferidos por membros de uma dada classe e, segundo, porque os intervalos salariais (de até 2SM a mais de 5SM) são insuficientes para afirmarmos que expressam classes sociais diferentes. Isto é, poderíamos dizer, que tratam-se de setores da classe trabalhadora e/ou classe média, mas seria difícil afirmarmos que se tratariam de classes baixas e altas, como o estudo alude em certo momento.
} 
Tabela 03 - Percepção a respeito dos espaços para práticas culturais e sociais por escolaridade

\begin{tabular}{|c|c|c|c|c|c|}
\hline Espaços & Percepção & $\begin{array}{l}\text { Analfabet } \\
0 \text { até } 4 \text { ạ } \\
\text { série do } \\
\text { 1grau }\end{array}$ & $\begin{array}{l}\text { Da } 5 \text { a até a } \\
8 \text { a série do } \\
1 \text { go grau }\end{array}$ & $\begin{array}{l}2 \text { o grau } \\
\text { completo ou } \\
\text { incompleto }\end{array}$ & $\begin{array}{l}\text { Superior } \\
\text { incompleto ou } \\
\text { pós-graduação }\end{array}$ \\
\hline \multirow[t]{5}{*}{ Espaços verdes } & Muito boa & 31,5 & 31,5 & 28,7 & 31,9 \\
\hline & Razoável & 35,3 & 38,4 & 36,3 & 35,9 \\
\hline & Mal & 30,2 & 29,3 & 33,6 & 30,6 \\
\hline & Não tem & 0,3 & 0,4 & 0,1 & 0,8 \\
\hline & NS/NR & 2,7 & 0,4 & 1,3 & 0,8 \\
\hline \multirow[t]{5}{*}{ Equipamentos esportivos } & Muito boa & 22,3 & 20,4 & 18,6 & 17,6 \\
\hline & Razoável & 30,6 & 31,8 & 29,0 & 34,8 \\
\hline & Mal & 40,3 & 41,7 & 48,2 & 41,8 \\
\hline & Não tem & 1,1 & 2,3 & 0,8 & 2,1 \\
\hline & NS/NR & 5,6 & 3,8 & 3,4 & 3,7 \\
\hline \multirow[t]{5}{*}{ Equipamentos culturais } & Muito boa & 15,6 & 16,8 & 15,1 & 15,2 \\
\hline & Razoável & 25,5 & 27,9 & 26,0 & 26,3 \\
\hline & Mal & 49,7 & 49,3 & 53,0 & 52,9 \\
\hline & Não tem & 1,2 & 1,7 & 1,4 & 2,1 \\
\hline & NS/NR & 7,9 & 4,3 & 4,5 & 3,5 \\
\hline \multirow{5}{*}{$\begin{array}{l}\text { Lugares de encontro e } \\
\text { vida associativa }\end{array}$} & Muito boa & 22,2 & 20,8 & 20,5 & 19,1 \\
\hline & Razoável & 27,3 & 33,9 & 31,4 & 40,7 \\
\hline & Mal & 42,0 & 39,7 & 43,1 & 35,1 \\
\hline & Não tem & 1,1 & 2,0 & 1,1 & 1,9 \\
\hline & NS/NR & 7,4 & 3,6 & 3,9 & 3,2 \\
\hline \multirow[t]{5}{*}{ Comércios } & Muito boa & 58,7 & 58,7 & 60,7 & 60,6 \\
\hline & Razoável & 29,8 & 31,0 & 31,0 & 30,9 \\
\hline & Mal & 9,9 & 10,2 & 7,7 & 8,0 \\
\hline & Não tem & 0,2 & 0,0 & 0,0 & 0,0 \\
\hline & NS/NR & 1,3 & 0,1 & 0,7 & 0,5 \\
\hline
\end{tabular}

Tabela Adaptada. Fonte: Pesquisa SIPS - IPEA, 2010.

Segundo os dados da tabela 05 , para $71 \%$ dos entrevistados 
os preços altos são um obstáculo ao acesso às ofertas culturais. Os preços altos para o acesso a espaços e atividades culturais é um grande - e histórico ${ }^{7}$ - obstáculo à classe trabalhadora e à juventude, pois expõe as profundas desigualdades de rendimentos entre a população, a depreciação dos valores salariais médios, dentre outras coisas. Soma-se à isso a política de caráter privatista na área da cultura que confere, através de mecanismos como a renúncia fiscal, milhões de reais a atividades culturais cujos valores dos ingressos são altos ${ }^{8}$.

Vale a pena conjecturar que, embora a maior parte dos museus brasileiros não cobre ingresso para acessá-lo (79,7\%), a política de precarização e privatização na cultura pode ampliar a prática de cobranças de ingresso nos museus brasileiros.

Já para $66,2 \%$ dos entrevistados, a distância entre os equipamentos culturais e a sua moradia constitui-se em um obstáculo à oferta cultural. É importante destacar, também, que $55,9 \%$ dos entrevistados concordam que o público frequentador dos equipamentos culturais é elitista e que isso se constitui em um obstáculo.

\footnotetext{
${ }^{7}$ No estudo Amor pela Arte, Pierre Bourdieu e Alain Darbel analisavam com cautela a questão do preço dos ingressos e uma suposta determinação deste na visitação, ao considerar outras despesas embutidas na visita aos museus: "Embora a maioria dos visitantes estejam de acordo ao julgar que os preços de ingresso são bastante baratos [...], podemos nos interrogar se, apesar de tudo, a renda familiar não exerce uma influência específica sobre os ritmos de frequência, já que o custo de uma visita inclui outras despesas, no mínimo tão importantes, tais como as despesas com transporte ou os custos implicados em qualquer saída familiar, e se um freio orçamentário não continuaria a agir, até mesmo, na hipótese da gratuidade dos ingressos [...] Em todo caso, nada seria mais ingênuo do que esperar que a simples queda no preço dos ingressos viesse a suscitar o aumento da frequência de museus por parte das classes populares" (2007, p. 43-44).

${ }^{8}$ Ver: http://www.concursosmuseologia.com.br/2014/05/trabalhadores-dacultura-e-os-museus-de.html.
} 
Tabela 04 - Percepções a respeito dos obstáculos ao acesso/oferta cultural

\begin{tabular}{|l|l|l|l|l|l|}
\hline $\begin{array}{l}\text { Percepção a respeito de } \\
\text { obstáculos ao acesso à } \\
\text { cultura }\end{array}$ & $\begin{array}{l}\text { Concorda } \\
\text { plenamente }\end{array}$ & Concorda & Discorda & $\begin{array}{l}\text { Discorda } \\
\text { plenamente }\end{array}$ & NS/NR \\
\hline $\begin{array}{l}\text { Os preços altos são um } \\
\text { obstáculo }\end{array}$ & 19,2 & 51,8 & 23,9 & 1,1 & 4,1 \\
\hline $\begin{array}{l}\text { O público frequentador é } \\
\text { elitista }\end{array}$ & 10,4 & 45,5 & 36,5 & 1,8 & 5,9 \\
\hline $\begin{array}{l}\text { Os equipamentos ficam } \\
\text { longe de onde moro }\end{array}$ & 13,1 & 48,5 & 33,0 & 2,3 & 3,0 \\
\hline $\begin{array}{l}\text { As atividades são } \\
\text { enfadonhas } \\
\text { desinteressante }\end{array}$ & 4,9 & 37,9 & 48,6 & 3,2 & 5,4 \\
\hline $\begin{array}{l}\text { Os horários em que } \\
\text { acontecem } \\
\text { inadequados }\end{array}$ & 7,7 & 44,1 & 40,5 & 1,8 & 5,8 \\
\hline $\begin{array}{l}\text { A região de localização do } \\
\text { equipamento é perigosa }\end{array}$ & 9,4 & 31,8 & 51,0 & 3,1 & 4,7 \\
\hline
\end{tabular}

Tabela Adaptada. Fonte: Pesquisa SIPS - IPEA, 2010.

Nas grandes cidades, certas zonas e áreas parecem ser essencialmente longes, ou distantes. Contudo, embora pareçam categorias estanques, perto e longe são noções relativas, isto é, dependem de pontos de referência com os quais se relacionam.

A percepção acerca da localização dos equipamentos sociais toma como referencial a moradia. Afinal, museus, bibliotecas e teatros estão perto ou longe de onde se mora. Portanto, à rigor, a discussão sobre o acesso aos equipamentos sociais - e neste caso específico aos museus - revela uma geopolítica da cultura, onde a localização geográfica dos museus e as moradias dos trabalhadores e da população pobre obedecem à lógica capitalista da produção e apropriação social do espaço. Nas palavras de Ferreira,

A percepção da espacialidade urbana deve considerar, então, a relação entre valor de uso e valor de troca para 
tornar o solo e suas benfeitorias mercadorias, pois é nesse momento que são tomadas as decisões quanto à alocação de atividades e recursos do solo. Considerando isso, entendemos que a cidade capitalista é constituída por áreas residenciais segregadas, aflorando assim, claramente, a sua complexa estrutura social em classes. Destarte, o espaço urbano é produzido tanto por ações realizadas no presente como também daquelas realizadas no passado e que deixaram suas marcas impressas nas formas espaciais do presente (2011, p. 120).

A segregação espacial produz graves consequências no que se refere ao acesso aos espaços de cultura. A esmagadora maioria da população nunca, ou raramente, foi ao cinema ou a um espetáculo de dança. E os percentuais são ainda maiores quando se trata do acesso à museus e centros culturais: 91,9\% dos entrevistados adultos nunca foram, ou raramente vão, a um museu ou centro cultural (IPEA, 2010).

A cidade é, segundo Robert Park, "a tentativa mais coerente e, em termos gerais, mais bem-sucedida de refazer o mundo em que vive, e de fazê-lo de acordo com seus mais profundos desejos". Contudo, a cidade é também o mundo em que o ser humano está condenado a viver, "assim, indiretamente e sem nenhuma consciência bem definida da natureza de sua tarefa, ao criar a cidade o homem recriou a si mesmo" (apud HARVEY, 2014, p. 28).

Para o geógrafo David Harvey, ter direito à cidade é bem mais do que um direito de acesso individual ou coletivo aos recursos que a cidade possui: "é um direito de mudar e reinventar a cidade mais de acordo com nossos mais profundos desejos. Além disso, é um direito mais coletivo do que individual, uma vez que reinventar a cidade depende inevitavelmente do exercício de um poder coletivo sobre o processo de urbanização" (2014, p. 28). 
Tabela 05 - Frequência de práticas culturais por região

\begin{tabular}{|l|l|l|l|l|l|l|}
\hline \multirow{4}{*}{ Prática } & Frequência & Sul & Sudeste & $\begin{array}{l}\text { Centro } \\
- \text {-Oeste }\end{array}$ & Nordeste & Norte \\
\hline \multirow{4}{*}{$\begin{array}{l}\text { Teatro/circo/sho } \\
\text { ws de dança }\end{array}$} & Todos os dias & 0,7 & 0,8 & 0,9 & 0,3 & 1,1 \\
\cline { 2 - 7 } & $\begin{array}{l}\text { Pelo menos uma } \\
\text { vez por mês }\end{array}$ & 11,1 & 11,2 & 20,9 & 11,5 & 20,2 \\
\cline { 2 - 7 } & $\begin{array}{l}\text { Raramente ou } \\
\text { nunca }\end{array}$ & 88,2 & 87,5 & 78,2 & 88,0 & 73,1 \\
\hline \multirow{4}{*}{ Cinema } & Todos os dias & 0,7 & 1,4 & 0,6 & 0,1 & 0,3 \\
\cline { 2 - 7 } & $\begin{array}{l}\text { Pelo menos uma } \\
\text { vez por mês }\end{array}$ & 15,1 & 17,7 & 25,1 & 9,8 & 28,9 \\
\cline { 2 - 7 } & $\begin{array}{l}\text { Raramente ou } \\
\text { nunca }\end{array}$ & 84,1 & 80,4 & 74,0 & 86,7 & 66,7 \\
\hline \multirow{2}{*}{$\begin{array}{l}\text { Museus/Centros } \\
\text { Culturais }\end{array}$} & Todos os dias & 0,5 & 0,3 & 0,6 & 0,4 & 0,8 \\
\cline { 2 - 7 } & $\begin{array}{l}\text { Pelo menos uma } \\
\text { vez por mês }\end{array}$ & 5,5 & 6,3 & 12,4 & 6,5 & 5,9 \\
\cline { 2 - 7 } & $\begin{array}{l}\text { Raramente ou } \\
\text { nunca }\end{array}$ & 94,0 & 92,9 & 87,0 & 92,8 & 88,2 \\
\hline
\end{tabular}

Tabela Adaptada. Fonte: Pesquisa SIPS - IPEA, 2010.

Porém, os dados apresentados demonstram que a organização das cidades brasileiras e a localização dos equipamentos culturais e de lazer não possibilitam a fruição cultural e limitam o direito à cidade à amplas camadas sociais.

Assim, para além das gastas cantilenas tautológicas que visam explicar a baixa visitação ou a fraca empatia da população para com os museus à uma carência de apreço pela "cultura", é preciso dizer que a política de produção e ocupação do espaço contribui para inviabilizar, na prática, o acesso à uma série de equipamentos culturais para as classes populares.

\section{A localização dos museus não é algo natural: o caso do Rio de}




\section{Janeiro}

De acordo com os dados apresentados pelo Cadastro Nacional de Museus $^{9}$, no ano de 2009, o Rio de Janeiro era o quinto estado brasileiro com o maior número de museus e o terceiro da região Sudeste, com 254 museus. Embora a cidade do Rio de Janeiro concentre 124 museus - perfazendo 48,8\% dos museus do estado - há uma capilaridade acima da média nacional nesta unidade federativa, onde $54 \%$ dos municípios fluminenses têm pelo menos uma unidade museal. Atualmente ${ }^{10}$, existem 149 museus na cidade do Rio de Janeiro e 315 no estado do Rio de Janeiro.

É importante destacar a natureza administrativa dos museus do estado do Rio de Janeiro, conforme gráfico abaixo. Gráfico adaptado.

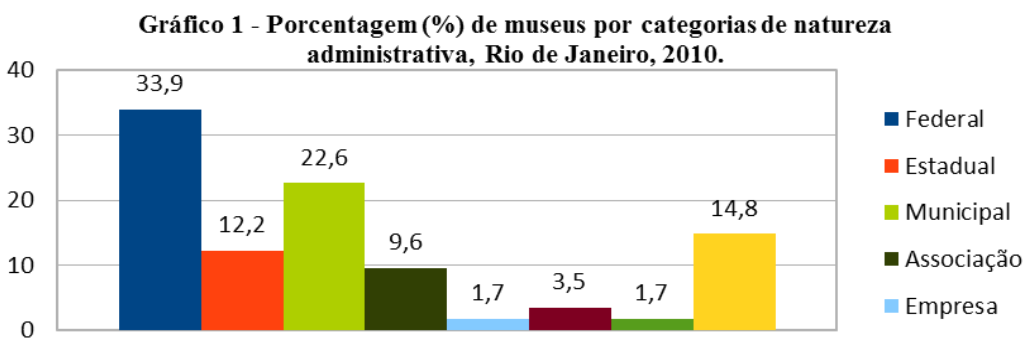

Fonte: (IBRAM, 2011).

Comparado aos números nacionais, onde $67,2 \%$ dos museus são públicos, o estado do Rio de Janeiro possui um percentual um pouco mais elevado: $68,8 \%$ dos museus são públicos; $16,5 \%$ são privados e $14,8 \%$ possuem outra natureza administrativa. Além disso, dentre os museus de natureza pública, 33,9\% são federais,

\footnotetext{
${ }^{9}$ Os dados do Cadastro Nacional de Museus utilizados, aqui, estão publicados nos volumes do Museus em número, do IBRAM (2011).

${ }^{10}$ Ver 2a edição do Cadastro Nacional de Museus:

http://sistemas.museus.gov.br/cnm/pesquisa/filtrarUf.
} 
revelando um percentual quase três vezes maior do que a média nacional, que é de $11,8 \%$.

Esses dados refletem, em certa medida, o papel que a capital do Estado do Rio de Janeiro teve na história brasileira. O Estado possui como capital a cidade do Rio de Janeiro, que durante todo o Império e também em parte do período republicano foi sede do governo central do País - até a inauguração de Brasília, em 1960. Esses fatos convergem com o percentual elevado de museus federais, somado à grande concentração de museus na capital (IBRAM, 2011, p. 418).

De fato, o alto percentual de museus federais reflete o papel que a cidade do Rio de Janeiro desempenhou como capital brasileira. Da chegada da família real, em 1808, até o ano de 1900, foram criados 11 museus no país, sendo que cinco ficavam localizados no Rio de Janeiro.

Nesse sentido, o surgimento dos museus no Rio de Janeiro não pode ser compreendido dissociando-o de uma ordem geopolítica internacional, que explica a chegada da família real portuguesa - amparada pela Marinha Britânica - ao Brasil, uma colônia na qual a realeza faria morada. Bem como, não se pode abstrair o papel político e econômico desempenhado pelo Rio de Janeiro, na ordem nacional do século XIX e a primeira metade do século XX.

O gráfico abaixo apresenta o crescimento quantitativo de museus no Rio de Janeiro até 2009. 
Gráfico 2: Criação de museus no Rio de Janeiro

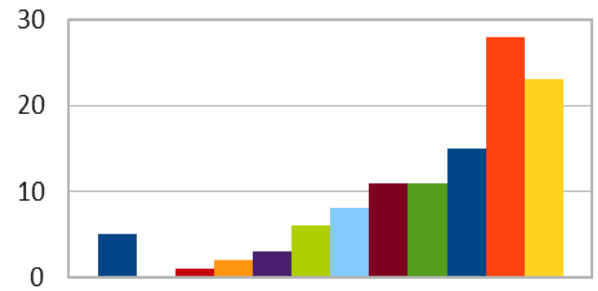

口 Até 1900

- 1901 a 1910

—1911 a 1920

1921 a 1930

— 1931 a 1940

Gráfico adaptado. Fonte: (IBRAM, 2011).

Segundo os números expostos, é possível observar que a maior parte dos museus do Rio de Janeiro foram criados nos últimos cinquenta anos. Entretanto, alguns dos mais importantes museus nacionais - e que estão localizados no Rio de Janeiro foram criados no século XIX e na primeira metade do século XX, como é o caso do Museu Nacional, do Museu Nacional de Belas Artes, do Museu Histórico Nacional e o Museu Casa de Rui Barbosa. Portanto, infere-se que a localização e a disposição dos museus na cidade do Rio de Janeiro obedeceu ao processo de urbanização e as consequentes transformações no espaço carioca.

Utilizarei, aqui, os dados obtidos no Guia Museus do Rio ${ }^{11}$, que é resultado da pesquisa realizada pelo programa de PósGraduação em Memória Social da Universidade Federal do Estado do Rio de Janeiro (UNIRIO) e que foi compartilhada pelo portal Museus do Rio, coordenado pela antropóloga Regina Abreu, e fundamentado pela atuação do Sistema Estadual de Museus (SIM-RJ). Os 48 espaços museológicos presentes no Guia dos museus foram divididos em áreas de planejamento, a saber: área de planejamento 1 envolvia os bairros do Cajú, Centro do Rio, Cidade Nova, Gamboa, Lapa, Mangueira, Rio Comprido, Santa

\footnotetext{
${ }^{11}$ Ver: http://www.museusdorio.com.br/joomla/images/stories/guiarj/museusrj2013.pdf.
} 
Teresa e São Cristóvão; área de planejamento 2 envolvia os bairros do Alto da Boa Vista, Andaraí, Botafogo, Catete, Copacabana, Cosme Velho, Flamengo, Gávea, Glória, Grajaú, Ipanema, Jardim Botânico, Lagoa, Maracanã, Rocinha, São Conrado, Tijuca e Urca; área de planejamento 3 envolvia os bairros de Del Castilho, Engenho Novo, Ilha do Fundão, Manguinhos, Maré, Penha e Piedade; área de planejamento 4 envolvia os bairros de Jacarepaguá, Recreio dos Bandeirantes e Taquara; área de planejamento 5 envolvia os bairros de Bangu, Barra de Guaratiba, Deodoro, Santa Cruz e Sulacap.

Vejamos: das 48 instituições museológicas mapeadas pelo Guia museus do Rio, a maior parte está concentrada nas áreas de planejamento 1 e 2, com destaque para o Centro do Rio de Janeiro, com 15 instituições museológicas. Ou seja, 87,5\% das instituições museológicas mapeadas localizam-se na área Central do Rio de Janeiro e na chamada Zona Sul, conhecida como a área mais "nobre" da cidade.

Com mais de 6 milhões de pessoas e com uma densidade demográfica de 5.265,8 habitantes por quilômetros quadrados, o Rio de Janeiro é a segunda cidade mais populosa do país. Atrás, apenas, da cidade de São Paulo.

A distribuição da população residente no Rio de Janeiro pode ser observada na tabela abaixo, em cinco áreas de planejamento - metodologia de divisão na qual se baseou o Guia dos Museus do Rio.

Em relação ao número de museus do estado do RJ para a população, a razão é de 1 museu para 60.710 pessoas. A razão entre a população da cidade do Rio de Janeiro é de 1 museu para, aproximadamente, 43.313 pessoas. Entretanto, conforme a tabela acima, a população residente nas áreas de planejamento 1 e 2 isto é, as áreas com o maior número de museus - representa apenas $20,6 \%$ da população da cidade do Rio de Janeiro ${ }^{12}$.

${ }^{12}$ No estudo Museus e seus visitantes (2005), isso já havia sido destacado: 
Tabela 06 - População residente, segundo as Áreas de Planejamento e Regiões Administrativas - 1991/2010.

\begin{tabular}{|l|l|l|l|}
\hline $\begin{array}{l}\text { Áreas de Planejamento } \\
\text { e Regiões } \\
\text { Administrativas }\end{array}$ & População Residente \\
\cline { 2 - 4 } & $\underline{1991}$ & $\underline{2000}$ & $\underline{2010}$ \\
\hline Total & 5480768 & 5857904 & 6320446 \\
\hline Área de Planejamento 1 & 306867 & 268280 & $\mathbf{2 9 6 4 0 0}$ \\
\hline Área de Planejamento 2 & 1033595 & 997478 & 1009170 \\
\hline Área de Planejamento 3 & 2321828 & 2353590 & $\mathbf{2 4 0 0 1 4 8}$ \\
\hline Área de Planejamento 4 & 526302 & 682051 & $\mathbf{9 0 9} 955$ \\
\hline Área de Planejamento 5 & 1292176 & 1556505 & $\mathbf{1 7 0 4 7 7 3}$ \\
\hline
\end{tabular}

Fonte: SIURB (2015).

Desde meados do século XX, a ocupação da cidade continuou seguindo o caminho traçado já no início desse mesmo século: o declínio da população residente na área central era cada vez maior e enquanto os subúrbios absorviam as classes mais baixas da população, a zona sul manteve-se como área preferida da classe mais abastada da cidade (FERREIRA, 2011, p. 103).

Considerando a cor e a raça da população dessas áreas observa-se um aviltante cenário de segregação racial: as regiões onde há maior concentração de museus são também aquelas onde a população é percentualmente mais branca. À guisa de exemplo, em bairros como o Centro e Botafogo, $59 \%$ e $79,6 \%$ da

\footnotetext{
"Dentre os visitantes entrevistados que residem no município do Rio de Janeiro, observa-se maior concentração de visitantes residentes nas áreas de planejamento AP2 (38,3\% dos residentes no município), que integra as regiões administrativas de Botafogo, Copacabana, Lagoa, Vila Isabel, Tijuca e Rocinha, e AP3 (30,4\%), que integra as regiões administrativas de Ramos, Penha, Inhaúma, Méier, Irajá, Madureira, Ilha do Governador, Anchieta e Pavuna.
} 
população é branca, respectivamente ${ }^{13}$.

Ao contrário, as áreas de planejamento 3 e 5 são majoritariamente mais negras, com bairros como Bangu e Santa Cruz onde, respectivamente, $61 \%$ e $65 \%$ da população é negra ${ }^{14}$.

A localização espacial das instituições museológicas é algo que não pode ser obliterado, sob pena de incompreensão da dinâmica das relações museológicas estabelecidas - ou rompidas - nas cidades. Como brevemente exposto, a disposição espacial dessas instituições expressa - como não poderia deixar de ser as assimetrias na produção e ocupação do espaço. Resta, agora, conectar isto às categorias de tempo e trabalho.

\section{Tempo, trabalho e transporte: as lições das Jornadas de Junho de 2013}

Nenhuma sociedade histórica tornou-se tão obcecada pelo controle do tempo quanto as sociedades capitalistas. E é assim porque o modo de produção capitalista exige um rigoroso controle do tempo da produção para que, da exploração do trabalho assalariado, erga-se uma sociedade de vendedores e compradores de mercadorias.

Nas palavras do economista anglo-saxão, Guy Standing:

Os fusos horários funcionam porque estamos naturalmente habituados à luz do dia e socialmente habituados ao conceito de dia de trabalho. O ritmo biológico está em harmonia com a luz do dia e a escuridão, quando o ser humano dorme e relaxa, recuperando-se das atividades do dia. Porém, a economia global não tem nenhum respeito pela

\footnotetext{
${ }^{13}$ Censo IBGE 2010, tabela 852:

http://www.ibge.gov.br/home/estatistica/populacao/censo2010/default.shtm.

${ }^{14}$ Compreendendo o racismo brasileiro, modulado por ideologias como o ideal de branquitude e o mito da democracia racial, adoto o procedimento dos movimentos negros organizados que somam as categorias pretas e pardas para comporem a categoria de negros.
} 
psicologia humana. O mercado global é uma máquina que funciona no esquema 24/7; nunca dorme ou relaxa; não tem nenhum respeito pela luz do dia ou escuridão, pela noite e pelo dia. Horários predeterminados são um estorvo, um rigor desnecessário, uma barreira ao comércio e ao totem da época - a competitividade - e são contrárias ao ditame da flexibilidade (2014, p. 178).

Embora algumas teorias contemporâneas se recusem a reconhecer a exploração dos trabalhadores e a extração de maisvalia (o gérmen do lucro), a exploração da classe trabalhadora e o roubo de seu tempo permanece uma verdade social incontornável.

De acordo com o sociólogo Ricardo Antunes, o capitalismo contemporâneo estabeleceu os contornos de uma nova morfologia do trabalho, caracterizada - dentre outras coisas pelo seguinte movimento:

Há, então, um movimento pendular que caracteriza a classe trabalhadora: por um lado, cada vez menos homens e mulheres trabalham muito, em ritmo e intensidade que se assemelham à fase pretérita do capitalismo, na gênese da Revolução Industrial, configurando uma redução do trabalho estável, herança da fase industrial que conformou o capitalismo do século XX. [...]

No outro lado do pêndulo, cada vez mais homens e mulheres trabalhadores encontram menos trabalho, esparramando-se pelo mundo em busca de qualquer labor, configurando uma crescente tendência de precarização do trabalho em escala global, que vai dos EUA ao Japão, da Alemanha ao México, da Inglaterra ao Brasil, sendo que a ampliação do desemprego estrutural é sua manifestação mais virulenta (2007, p. 13). 
Essa nova morfologia compreende, nos termos de Antunes (2007), a classe que vive do trabalho: o operariado industrial, rural, os assalariados de serviço, os trabalhadores terceirizados, temporários etc. Ou seja, o conjunto dos trabalhadores.

Isso traz inúmeras implicações para o mundo da cultura e para os museus ${ }^{15}$. E aqui é importante tecer algumas considerações sobre o trabalho e o tempo livre no Brasil contemporâneo, já que o ritmo e a intensidade do trabalho aumentam significativamente.

Segundo o Sistema de Indicadores de Percepção Social sobre trabalho e tempo livre, do IPEA, 45,4\% dos entrevistados ${ }^{16}$ afirmaram ter dificuldade para se desligarem totalmente do trabalho remunerado, mesmo após o fim da sua jornada diária de trabalho. Não obstante, $37,7 \%$ dos entrevistados sentem que o tempo livre vem diminuindo recentemente, devido ao tempo despendido com o trabalho remunerado (IPEA, 2012).

De forma um pouco menos óbvia, essa percepção também parece estar relacionada a características sociodemográficas dos entrevistados, como a região geográfica de residência. Ao contrastar os que habitam regiões não-afluentes (Norte, Nordeste e Centro-Oeste) e os que moram em regiões afluentes (Sul e Sudeste), registra-se os últimos têm uma chance 1,6 maior de mencionar que seu tempo livre vem diminuindo, devido ao tempo gasto com o trabalho (2012, p. 12, grifo nosso).

Contudo, a avaliação feita no SIPS acerca da conjuntura na

\footnotetext{
${ }^{15}$ Ver: A situação dos trabalhadores museólogos: uma análise sobre trabalho e precarização: http://www.edemocracia.com.br/sociologia/anais_2015/pdf/AN4B.pdf.

${ }^{16}$ Essa pesquisa foi realizada com 3.775 domicílios, em 212 municípios brasileiros de todas as unidades federativas brasileiras, com uma margem de erro de $5 \%$.
} 
qual a análise é realizada é frágil, posto que ao falar da redução do desemprego, da informalidade e da expansão do trabalho formal, nada fala sobre o tipo de emprego formal que foi criado nos últimos dez anos e os rendimentos médios nesse período. De fato, houve uma redução do tempo dedicado ao trabalho no país. Entretanto, como nos esclarecia Antunes, isso não significa, necessariamente, que haja redução na intensidade e nos ritmos do trabalho:

Algo similar ocorre se, após a redução pela metade da jornada de trabalho, houver uma duplicação da intensidade das operações anteriormente realizadas pelo mesmo trabalho. De modo que lutar pela redução da jornada de trabalho implica também e decisivamente lutar pelo controle (e redução) do tempo opressivo de trabalho; isso porque a redução formal do horário de trabalho pode corresponder "a um aumento real do tempo de trabalho despendido durante esse período" (2009, p. 173, grifo nosso).

De acordo com uma pesquisa realizada pela consultoria Plus Marketing, na manifestação de 20 de junho de 2013 na cidade do Rio de Janeiro, a maioria dos manifestantes estava no mercado de trabalho $(70,4 \%)$ e ganhava até um salário mínimo (34,3\%). Somase a isso que 30,3\% dos manifestantes recebiam entre 2 e 3 salários mínimos. Ou seja, mais de $64 \%$ encontram-se numa faixa de renda que lhes impõem as experiências das carências de todos os serviços públicos em seu cotidiano (transporte público, saúde, educação, cultura etc.) (ANTUNES; BRAGA, 2013).

Não à toa, as ondas de manifestações populares que varreram o Brasil em junho de 2013, traziam consigo uma forte contestação da mobilidade urbana expressas, por exemplo, no lema inicial: "não é por 0,20 centavos".

Uma pesquisa nacional realizada pelo Ibope durante as passeatas do mês de junho de 2013 mostrou que 
os problemas mais citados pelos manifestantes eram a saúde (78\%), a segurança pública (55\%) e a educação (52\%). Ademais, $77 \%$ dos entrevistados mencionaram a melhoria do transporte público como a principal razão dos protestos. Estamos diante de um autêntico processo de mobilização do proletariado precarizado em defesa tanto de seus direitos à saúde e à educação públicas e de qualidade quanto pela ampliação de seu direito à cidade (BRAGA, 2013, p. 82).

A juventude das chamadas Jornadas de Junho de 2013 se lançou às ruas para cobrar dos governos a melhoria social que Ihes fora acenada, transformando a rua a principal arena política do país naquele momento.

A rua é um espaço público que histórica $\mathrm{e}$ frequentemente se converte pela ação social em um comum do movimento revolucionário, assim como em um espaço de repressão sangrenta. Sempre houve uma luta por quem cuidará e para quem a produção e o acesso ao espaço e aos bens públicos devem ser regulados. A luta para apropriar os espaços e bens públicos urbanos tendo em vista um objetivo comum está em curso. Todavia, para proteger o comum, quase sempre é crucial proteger o fluxo de bens públicos que corroboram as qualidades do comum (HARVEY, 2014, p. 144-145, grifo nosso)

O tema do transporte trás no seu verso a localização espacial das moradias e dos equipamentos sociais, refletindo e revelando o que Harvey chama por desenvolvimento geográfico desigual do capitalismo.

Vastas concentrações de capital e trabalho têm se 
juntado em áreas metropolitanas extremamente complexas, enquanto os sistemas de transporte e comunicações, estendidos em amplas redes, permitem que as informações e as ideias, assim como os bens materiais e até mesmo a força de trabalho, se desloquem com relativa facilidade. Fábricas e campos, escolas, igrejas, centros comerciais e parques, rodovias e ferrovias se espalham por uma paisagem que tem sido indelével e irreversivelmente criada seguindo os ditames do capitalismo. Mas essa transformação física também não se produziu de modo regular. Vastas concentrações de força produtiva contrastam aqui com regiões relativamente vazias ali. Concentrações de atividades fixas em um lugar contrastam com um desenvolvimento relativamente flexível e disperso em outro (2013, p. 477-478).

Como Harvey ressalta, os sistemas de transportes permitem que a força de trabalho se desloque com relativa facilidade. Afinal, uma série de fatores concorrem para tornar a mobilidade urbana dos trabalhadores um tormento quase absoluto, tais como a apropriação das terras, a política do automóvel, a qualidade dos meios de transporte público, seus preços etc.

A força de trabalho é uma mercadoria, mas as condições que governam sua mobilidade são muito especiais. É a única mercadoria que pode levar a si mesma para o mercado sem a ajuda de ninguém. Por isso, o termo "mobilidade do trabalho" ocupa uma posição especial no discurso econômico. Na teoria burguesa, e frequentemente no linguajar comum, ele se refere à liberdade do trabalhador de vender a sua força de trabalho quando, onde, por qualquer propósito e a quem lhe aprouver. Essa liberdade de 
contrato é fundamental para as concepções burguesas dos direitos humanos e das liberdades civis. Marx não nega a importância dessas liberdades positivas, mas insiste em que sejam vistas em relação a outro lado mais obscuro das coisas. O trabalhador é "livre em dois sentidos: de ser uma pessoa livre, que dispõe de sua força de trabalho como sua mercadoria, e de, por outro lado, ser alguém que não tem outra mercadoria para vender, livre e solto, carecendo absolutamente de todas as coisas necessárias à realização de sua força de trabalho". "Livre" pelo processo de acumulação primitiva do controle sobre os meios de produção (incluindo o acesso à terra), a maioria dos trabalhadores não tem opção a não ser vender a sua força de trabalho ao capitalista para poder sobreviver (2013, p. 485-486).

Segundo dados do Sistema de Indicadores de Percepção sobre mobilidade urbana, do IPEA, 41\% dos entrevistados de cidades acima de $100 \mathrm{mil}$ pessoas consideram o transporte público ruim e/ou muito ruim. Além disso, para $48 \%$ destes entrevistados, o transporte público não permite que se desloquem facilmente por toda a cidade (2012).

O tempo despendido no deslocamento entre a moradia e o local de trabalho é um tempo que não é contabilizado na jornada do trabalhador assalariado brasileiro. Assim, nas grandes metrópoles, quando um trabalhador gasta 02 horas para ir ao local de trabalho e mais 02 horas para voltar à sua moradia, despende nada menos do que 04 horas no seu deslocamento diário. Somando-se à jornada média de 08 horas diárias, temos um aviltante caso de seres humanos que dedicam metade do seu dia (12 horas) ao trabalho assalariado.

Entende-se aqui que a liberdade dos trabalhadores no capitalismo significa a liberdade de vender o seu bem mais 
precioso àqueles indivíduos que possuem os meios econômicos para comprá-la. Assim, a liberdade dos trabalhadores de usufruir da produção social posta pelos equipamentos culturais está subsumida, em última análise, a estas pedras angulares do capitalismo: a exploração de sua força de trabalho e o desenvolvimento geográfico desigual das cidades.

\section{Considerações finais}

Em geral, as análises sobre a visitação dos museus e dos diferentes equipamentos culturais se concentram mais especificamente sobre a capacidade das instituições em atrair públicos visitantes através de eficientes ações comunicativas, e menos sobre as condições sociais nas quais a visitação é possível ou inviabilizada.

Com isso, reproduz-se a arraigada visão de que os museus "pairam" sobre a sociedade. Assim, parece que os conflitos e as contradições sociais localizam-se da porta para fora dessas insignes instituições, reforçando assim a ideologia da neutralidade dos museus.

Em seu consistente estudo sobre o público de museus na Europa, na década de 1960, Pierre Bourdieu e Alain Darbel assim avaliaram a questão, sob o ângulo da relação instrução-classes sociais:

Considerando que nada é mais acessível do que os museus e que os obstáculos econômicos - cuja ação é evidente em outras áreas - têm, aqui, pouca importância, parece que há motivos para invocar a desigualdade natural das "necessidades culturais". Contudo, o caráter autodestrutivo dessa ideologia salta aos olhos: se é incontestável que nossa sociedade oferece a todos a possibilidade pura de tirar proveito das obras expostas nos museus, ocorre que somente alguns têm a possibilidade real de concretizá-la (2007, p. 69). 
O tema da visitação aos museus foi analisado aqui por outro ângulo, muito mais modesto. Por isso, deliberadamente não pus em questão os "conteúdos" dos museus que, em sua quase integralidade, limitam-se à exortação da cultura das classes dominantes, implicando num significativo distanciamento do público oriundo da classe trabalhadora.

Me detive aqui em algo mais elementar. E vale ressaltar que, embora a gama de dados apresentadas neste estudo possibilite o estabelecimento de algumas considerações, será preciso desenvolver pesquisas mais focalizadas sobre as realidades das cidades, dos museus e de seus públicos se quisermos avançar em mais conclusões.

Penso que é fundamental considerarmos a localização dos museus e o desenvolvimento geográfico desigual das grandes cidades nos estudos da Museologia. Afinal, a localização dos museus não é apenas geográfica, mas política. Isto é, fruto de circunstâncias históricas e de escolhas políticas e econômicas que não podem ser ignoradas.

Além disso, o trabalho assume um papel importante nesta investigação, pois é do modo específico de produzirmos e reproduzirmos nossas condições de existência que o tempo livre e a moradia, por exemplo, podem se tornar categorias cientificamente significativas para pensarmos a relação entre os museus e a sociedade.

O acesso ao lazer e à fruição cultural tem sido, na prática, negado à classe trabalhadora e pobre, e isso nada tem a ver com uma falta de predisposição cultural sua, mas com o modo como organizamos socialmente a nossa produção, como construímos e apropriamos o espaço, e como regulamos nosso tempo.

\section{Referências}

ANTUNES, Ricardo. Dimensões da precarização estrutural do trabalho. In: DRUCK, Graça.; FRANCO, Tânia (Orgs.) A perda da razão social do trabalho: terceirização e precarização. São Paulo: Boitempo, 2007. 
ANTUNES, Ricardo; BRAGA, Ruy. La explosión social en Brasil: Primeras anotaciones (para un análisis posterior). Nuestra America. № 35, jul 2013. Colômbia: 2013.

BOURDIEU, Pierre; DARBEL, Alain. 0 amor pela arte: os museus de arte na Europa e seu público. São Paulo: USP, Porto Alegre: Zouk, 2007.

BRAGA, Ruy. A política do precariado: do populismo à hegemonia lulista. São Paulo: Boitempo, 2012.

BRAGA, Ruy. Sob a sombra do precariado. In: MARICATO, Ermínia (Org). Cidades Rebeldes: Passe livre e as manifestações que tomaram as ruas do Brasil. São Paulo: Boitempo, 2013.

FERREIRA, Alvaro. A cidade no século XXI: Segregação e banalização do espaço. Rio de Janeiro: Consequência, 2011.

HARVEY, David. Cidades Rebeldes: do direito à cidade à revolução urbana. São Paulo: Martins Fontes, 2014.

HARVEY, David. Os limites do capital. São Paulo: Boitempo, 2013.

IBRAM. Museus em números volume 1. Brasília: IBRAM, 2011.

IBRAM. Museus em números volume 2. Brasília: IBRAM, 2011.

IBRAM. Museus em números volume 2B. Brasília: IBRAM, 2011.

IPEA. Sistema de Indicadores de Percepção Social - Cultura. IPEA: 2010.

Disponível em:

<<http://www.ipea.gov.br/portal/images/stories/PDFs/SIPS/101117_sips_cultur a.pdf $>$. Acesso em: 18 ago 2015.

IPEA. Sistema de Indicadores de Percepção Social - Mobilidade Urbana. IPEA:

2012. Disponível em:

<<http://www.ipea.gov.br/portal/images/stories/PDFs/SIPS/120119_sips_mobili dadeurbana.pdf $>>$. Acesso em: 20 ago 2015.

IPEA. Sistema de Indicadores de Percepção Social - Trabalho e Tempo livre.

IPEA: 2012. Disponível em:

<<http://www.ipea.gov.br/portal/index.php?option=com_content\&view=article \&id=24440\&catid=120\&ltemid=2>>. Acesso em: 20 ago 2015.

KÖPTCKE, Luciana Sepúlveda; CAZELLI, Sibele; LIMA, José Matias de. Museus e seus visitantes: relatórios de pesquisa perfil-opinião 2005. Brasília: Gráfica e Editora Brasil, 2009. Disponível em:

<<http://www.fiocruz.br/omcc/media/5_relatorio_museu.pdf >>. Acesso em: 23 ago 2015.

PIRES, Vladimir Sibylla. Para o levante da multidão, uma museologia da monstruosidade? In: CHAGAS, Mário (Org). Museologia Social. Cadernos do CEOM. Chapecó: Unochapecó, ano 27, n 41, dez 2014.

PORTO-GONÇALVES, Carlos Walter. Os (des)caminhos do meio ambiente. São Paulo: Contexto, 2008.

SANTOS, Milton. Por uma Geografia Nova: Da Crítica da Geografia a uma Geografia Crítica. São Paulo: USP, 2012. 
SIURB. Sistema Municipal de Informações Urbanas. Disponível em: <<http://portalgeo.rio.rj.gov.br/indice/flanali.asp?codpal=459\&pal=\%C1REA\%20 \%20DE\%20PLANEJAMENTO\%20-\%20AP>>. Acesso em 24 ago 2015.

STANDING, Guy. O Precariado: a nova classe perigosa. Belo Horizonte: Autêntica, 2014.

\section{Autor}

Bacharel em Museologia pela Universidade Federal do Estado do Rio de Janeiro (UNIRIO). Bacharel em Ciências Sociais pela Universidade Federal do Rio de Janeiro (UFRJ), Mestre em Ciências pelo CPDA/UFRRJ. Doutorando em Sociologia pela Universidade Estadual de Campinas (UNICAMP). Sou professor de dedicação exclusiva da Coordenadoria Especial de Museologia da Universidade Federal de Santa Catarina (UFSC). Ministro aulas nas cadeiras de Teoria e Comunicação Museológica, Metodologia Científica e de Pesquisa. Desenvolvo pesquisas sobre a formação dos museus e sobre o trabalho na Museologia e nos museus brasileiros. 